\title{
ENVIRONMENTAL REMEDIATION AND POSSIBLE USE OF TERRESTRIAL MICROBIAL FUEL CELLS
}

\author{
GIORGIA AIMOLA ${ }^{1}$, GABRIELE GAGLIARDI $^{2}$, ANDREA PIETRELLI $^{3,4}$, VALERIA ANCONA $^{1}$, \\ ANNA BARRA CARACCIOLO ${ }^{1}$, DOMENICO BORELLO ${ }^{2}$, VINCENZO FERRARA $^{5}$ \& PAOLA GRENNI ${ }^{1}$ \\ ${ }^{1}$ Water Research Institute (IRSA), National Research Council (CNR), Italy \\ ${ }^{2}$ Department of Mechanical and Aerospace Engineering, Sapienza University of Rome, Italy \\ ${ }^{3}$ Univ Lyon, INSA Lyon, Université Claude Bernard Lyon 1, Ecole Centrale de Lyon, France \\ ${ }^{4}$ ECP Lab, Université Lumière Lyon 2, France \\ ${ }^{5}$ Department of Information Engineering, Electronics and Telecommunications, \\ Sapienza University of Rome, Italy
}

\begin{abstract}
Many soils contain a wide number of organic and inorganic chemicals and potential toxic elements due to industrial, agricultural and numerous anthropogenic activities. The recovery of polluted sites is an urgent need to be addressed and the development of innovative remediation technologies, which exploit nature-based solutions, is strongly encouraged, in line with the new EU Circular Economy Action Plan. Terrestrial microbial fuel cells (TMFCs) can be a valuable tool for recovering soils polluted by various organic and inorganic contaminants. TMFCs benefit from capabilities of microbial biofilms developed on the electrodes, which use the terminals as catalysts for metabolic activities, including contaminant degradation. This process produces energy, thanks to conversion of chemical bond energy (stored in the bonds of organic compounds) into electrical ones. This work describes construction materials, remediation capabilities and technology of the TMFCs, reporting the last advances in TMFCs such as soil-based reactors or in combination with plants (plant microbial fuel cell (PMFC)). Some aspects related to microbiological activities for pollutant biodegradation, plant-microbial interactions, energy production, and fields of application will be shown. Finally, abiotic factors which can improve bioremediation activities are also considered. Furthermore, limitations and issues for large-scale applications, as well as for stacking and scaling-up are discussed.

Keywords: electrogenic bacteria, microbial degradation, green technology, bioremediation, microbial fuel cell.
\end{abstract}

\section{INTRODUCTION}

In recent years, great attention has been provided to develop new sustainable strategies for soil recovery from contamination. Remediation strategies can be in situ (without excavation of soil or with excavation of soil and treated in the site) or ex situ (if contaminants or contaminated matrices are taken from a site and brought elsewhere for their treatment). In the following paragraphs bioremediation and plant-assisted bioremediation, in line with the Green Economy and the new EU Circular Economy Action Plan (https://ec.europa.eu/ environment/circular-economy/pdf/new_circular_economy_action_plan.pdf) combined with terrestrial microbial fuel cells are described as possible technologies for recovery soils from organic and inorganic contaminants.

\section{REMEDIATION PROGRESSES}

\subsection{Bioremediation}

Bioremediation relies on the use of bacteria, fungi or plants (including in some cases their enzymes or growth stimulants) for degrading, transforming, sequestering, mobilizing contaminants. It exploits natural recovery abilities of microorganisms to degrade organic contaminants. Biotransformation is the transformation of a contaminant into another less 
toxic or non-toxic molecule. Biodegradation is the breakdown of a parental molecule into smaller (less complex) or inorganic molecules (mineralization). Only microorganisms can mineralize organic compounds into inorganic constituents $\left(\mathrm{CO}_{2}\right.$ and $\left.\mathrm{H}_{2} \mathrm{O}\right)$. In some cases, the organic contaminant is used as carbon or nitrogen source for microbial community (metabolism), but in other cases degradation occurs by co-metabolism, i.e. the oxidation of a substance without its energy utilization and microbial growth.

Biodegradation can occur in soil, because natural microbial communities (and in particular Bacteria) have a great physiological versatility and catabolic potential, leading to breakdown of an enormous number of organic molecules, including persistent organic pollutants [1]-[3]. Bioremediation includes bioaugmentation (addition of previously selected microorganisms for removing specific contaminants) and biostimulation (addition of nutrients, oxygen, electron donors or acceptors).

Bioremediation effectiveness depends on site-specific abiotic and biotic conditions of soil and type and amount of contaminants. For example, contaminant concentrations above the toxicity tolerance level of microorganisms (which can vary with the compound bioavailability) will make biodegradation ineffective. Moreover, some microbes need specific conditions for being effective (e.g. specific acid/basic conditions, saline presence, organic carbon or water content, presence/absence of oxygen).

Terrestrial microbial fuel cells (TMFCs) require for their activity (electricity production), a high soil moisture in order to permit microorganisms to develop a biofilm on the anode (which is used as an electron acceptor in anaerobic conditions) and to promote the flows of protons through soil directly to the cathode. The latter is the site in which, in aerobic conditions, electrons and protons react with oxygen producing water. The oxidation of organic contaminants by electroactive bacteria is performed in anaerobic conditions, thanks to a high soil moisture. A soil moisture close to the maximum water holding capacity of soil and a constant environmental temperature favour microbial activity and promote TMFC performance (in terms of electricity production and organic contaminant degradation) [1], [3]. Even if in the case of TMFCs used for organic contaminant biodegradation the electricity outputs can be relatively low, this technology can be effective for bioremediation purposes. Mathematical models for MFCs are very useful for their design, control and optimization [4]. These models (e.g. Monod and Monod-type models) can describe microbial growth kinetics. If microbial gene regulatory networks are known and modelled, a more efficient MFC could be developed in order to scale up this technology. For example, advanced bio-based models which connect gene regulation of specific metabolic pathways with microbial growth kinetics enables a more accurate estimation of substrate biodegradation, microbial growth kinetics, and necessary gene and enzyme expression. The prediction of gene and enzyme expression can also be used in synthetic and biological systems for process optimization.

\subsection{Plant assisted bioremediation}

Plant assisted bioremediation (PABR) is a green remediation tool that relies on synergistic relations between naturally occurring microorganisms of soil, water, sludge or sediments and plant roots [5], [6], resulting in various contaminant clean up processes (phytoextraction, phytostabilization, phytoaccumulation, rhizodegradation). Plants release through their roots several low-molecular-mass compounds (e.g. sugars and polymerized sugar, amino acids and organic acids) together with root border cells and dead root cap cells. These root exudates positively affect rhizosphere microbiota because they are used as carbon sources, stimulating it for an active decontamination process [7]. PABR technology can recover matrices polluted by both organic and inorganic contaminants [8] and it has been successfully tested in 
greenhouse and field studies for promoting polychlorinated biphenyls (PCBs) degradation and heavy metals phytocontainment [7], [9]-[11].

A recent study [12] confirmed the effectiveness of the poplar clone Monviso in stimulating the natural belowground microbial community, in removing PCBs and heavy metals and improving the overall soil quality. The biomass generated by this PABR can be also used for producing energy. A fluidized-bed gasification treatment was successfully conducted on poplar biomass pruning residues. However, deep investigations are needed in different sitespecific scenarios for ensuring a zero impact on environment (e.g. for trapping possible pollutant residues in ashes during the gasification process) [13].

Adding organic amendments such as biochar or compost can increase plant and microbial biomass in rhizosphere, with positive effects on the PABR performance [2].

\section{POLLUTION MANAGEMENT OF SOIL WITH MFC}

\subsection{TMFC for remediation of organic pollutants}

TMFCs can generate electricity and, at the same time, recover soil from different kind of pollution [14]-[16]. Specific microorganisms naturally present in soils (exo-electrogens bacteria) can use anode and cathode as electron acceptors during their metabolic activities, inducing contaminant transformation or degradation. TMFCs have to be designed ad hoc taking into consideration biotic and abiotic (e.g., $\mathrm{pH}$, temperature, moisture) conditions for each specific contaminant.

TMFCs have proved to promote degradation also of some persistent organic compounds (POPs) [17]. In fact, the condition of anoxia necessary to favour degradation of these compounds is possible. The anode electrode is placed in anoxic conditions in soil where the oxidation of organic compounds by microorganisms occurs [18]. Meanwhile, the cathode is in contact with an accessible source of oxygen (water or air) and it works as a terminal electron acceptor [19]. Dichloroethane (DCA) degradation was tested with TMFCs in aerobic and anaerobic conditions in the presence/absence of microbial communities grown on the anode. Each condition was also tested in open and closed circuits. The microbial presence showed a clear improvement in TMFC performance in terms of DCA degradation and energy production (98\% and $93 \%$ for closed and open circuit, respectively). In the absence of bacteria, no DCA removal was found in open circuit, while the removal increased to $95 \%$ in closed circuit [20].

Other authors reported phenol removal using TMFCs [21] with a higher degradation and microbial activity $(90.1 \%)$ in closed than in open circuit $(27.6 \%)$ condition. Moreover, Yu et al. [22] tested the degradation chlorinated phenol by TMFCs, confirming that degradation of this molecule occurs through a dehalogenation at the anode [23].

PCB degradation in TMFCs was found higher in the presence of surfactants (Tween80, sodium dodecyl sulfate SDS), used for stimulating microbial metabolic activity [24]. Cao et al. [25] used TMFCs to remediate soil contaminated by the pesticide hexachlorobenzene (HBC). A higher HBC removal (71\%) was found in the presence of an anaerobic sludge; lower degradation rates were found in the open circuit $(52 \%)$ or the absence of anaerobic sludge $(39 \%)$. The presence of anode promoted the exo-electrogenic microbial activity, increasing metabolic rates of anaerobic bacteria and enhancing HCB degradation via the reductive dechlorination pathway under anaerobic condition.

Polycyclic aromatic hydrocarbon $(\mathrm{PAH})$ degradation was more efficient in anaerobic condition than in aerobic one [26]. Moreover, PAH degradation was higher adding sulphates and nitrates because bacteria used them in their metabolism. PAH (anthracene, phenanthrene, 
pyrene) degradation using MFCs was found with higher removal rates in the closed condition [22]. Zhao et al. [27] studied the phenanthrene and pyrene degradation using plant microbial fuel cells. The plant presence in TMFCs increased the crude-oil degradation rate by $45 \%$ compared to the system without plants due to an improvement in the electron-transfer efficiency. In fact, the charge-transfer resistance in the TMFCs was significantly reduced by $57.9 \%$ with the addition of plants.

Recently, Borello et al. [1] reported the removal of DDE (2,2-bis (dichlorodiphenyldichloroethylene or p-chlorophenyl)-1,1-dichloroethylene), the main toxic metabolite of the pesticide DDT (dichlorodiphenyl-trichloroethane). After 2 months from the beginning of the experiment, the results showed that the TMFCs promoted a significant degradation of the pesticide (39\%), compared to conditions in absence of TMFCs. At the same time of the pesticide degradation, an increase in microbial activity was observed.

TMFCs were also effectively in petroleum hydrocarbon biodegradation [28]. A good removal of alkanes, aromatics, asphaltene and polar materials was found after 223 days. Moreover, adding different biochars enhanced both the removal efficiency and the electrical generation. Similar results were found by Lu et al. [29] in which tubular BESs with carbon cloth anode or biochar anode were used in a field experiment where raw water saturated soils contaminated by petroleum hydrocarbons were used. The removal rate of the total petroleum hydrocarbons (11.46 g/kg dry soil) almost doubled in soils close to the anode $(63.5-78.7 \%)$ than that in the open circuit positive controls (37.6-43.4\%) during a period of 64 days.

\subsection{TMFC for remediation of inorganic pollutants}

Heavy metal removal from soil is more difficult than organic pollutants because they can only be converted into less toxic forms or immobilized to reduce their bioavailability. Cathode reduction is one of the main mechanisms to remediate heavy metals [30]. The final electron acceptors can be oxygen or metal ions, depending on redox potential of a metal ion: ions with low redox potential tend to use oxygen as terminal acceptor of electrons, while ions with high redox potential in the cathode area can compete with oxygen as terminal electron acceptors. These ions, through a reduction, can be transformed from the ionic form to the elementary state and they can precipitate and be easily separated from the soil [17], [31], [32]. The reaction could not occur at the cathode side when the redox potential of heavy metal (e.g. $\mathrm{Pb}(\mathrm{II}), \mathrm{Cd}(\mathrm{II})$ and $\mathrm{Zn}(\mathrm{II})$ ) is lower than the anode potential. To facilitate soil removal of such metals, the application of air cathode was proposed [33]. Wang et al. [34] investigated the electrodynamic effect on $\mathrm{Cr}$ and $\mathrm{Cd}$ degradation and the air-cathode MFCs were effectively. Moreover, the remediation performance was enhanced by decreasing $\mathrm{pH}$ and extending operation time. Remediation of different $\mathrm{Cr}(\mathrm{VI})$ concentrations in soil was also analysed using a plant-MFC [35]. The latter achieved a $99 \% \mathrm{Cr}(\mathrm{VI})$ and $27.4 \%$ total $\mathrm{Cr}$ removals in soils, suggesting that plant uptake, along with the common electrochemical process of a MFC, enhanced the effect of decontamination.

Soil contamination with copper $(\mathrm{Cu})$ is one of the most widespread types of pollution; this metal can migrate under the electric field of a soil MFC from the anode to the cathode [36], making this technology easily used to remove copper from soil. In this regard, Zhang et al. [37] found that the heavy metal migration in soil was mainly due to the electricity generation of MFC, and the migration efficiency increased with increasing electricity generation.

Cadmium and lead $(\mathrm{Cd}$ and $\mathrm{Pb})$ migration in TMFCs from the anodic to the cathodic chamber was also found and it was due to the weak electric field [38]. During this migration, a decrease in $\mathrm{pH}$ and electric conductivity at the anode was observed; in the cathode area, instead, an increase in $\mathrm{pH}$ and electric conductivity were found. Although the migration was 
observed for both metals, the removal efficiency was different, probably due to their mobility and treatment times.

Since the removal efficiency of the MFC for heavy metals in soil depends on the intensity of the electric field, electron acceptors with high reaction kinetic constants could be used instead of oxygen, or the area of the cathode could be expanded to increase the intensity of the electric field inside the MFC, promoting an efficient heavy metal remediation [39].

\subsection{Plant microbial fuel cell for soil recovery}

TMFCs have been recently coupled with PABR technique. Plant microbial fuel cell (PMFC) is a promising TMFC variant, which exploits the close relationships and synergic interactions between bacteria and plant in the rhizosphere for degrading contaminants. The rhizosphere secretions in PMFCs can be directly used as electron donors for the biofilm microbial community [40]. PMFCs integrate the photosynthesis mechanism and the TMFCs, to convert solar energy to a carbon source available for bacteria. Thanks to root exudates, bacteria transform/degrade organic matter and contaminants in soil, producing bioenergy by microbial oxidation at the anode region [41]-[43]. Light is a key factor for the technology success because is fundamental for photosynthesis and producing plant biomass and root exudates [42]. The light intensity, photoperiodism and photosynthetic pathway can affect system performance [42], [44]-[46]. Several studies showed the importance of trying different types of plants based on their photosynthetic activity (CAM, C3, C4) [38], [45], [47]. In a PMFC, fundamental factors in determining power outputs are roots, their development and exudates production, which in turn affect the relationships between plant and microbial community and the photosynthetic rates. Although a better performance was observed in $\mathrm{C} 4$ plants (in which the $\mathrm{CO}_{2}$ is first fixed into a compound containing four carbon atoms before entering the Calvin cycle of photosynthesis), it also depends on others factors, such as electrode materials and operating parameters (temperature, $\mathrm{pH}$, conductivity, etc.) [42], [48]. Furthermore, the trend of voltage generation is strictly dependent on the biomass developed, root morphology, released exudates and the microbial activity [42], [48].

PMFC efficiency was tested in closed and open circuit systems to remediate $\mathrm{Cr}(\mathrm{VI})$ polluted soil, using two plant species (Pennisetum alopecuroides and Phragmites communis) selected for their fast growth, high biomass, root development and a great capability to remediate contaminants in plant-assisted bioremediation [35]. Different types of electrode materials were also tested. The results showed that more than $90 \%$ of $\operatorname{Cr}(\mathrm{VI})$ could be removed in PMFCs; in the open circuit system with plants the removal rate was about 20-30\%, proving that plants had an important role in contaminant uptake. The contaminant removal efficiency in the plant absence was approximately $7 \%$ due to the absorption onto electrodes and/or the reduction by Cr-reducing microorganisms. Furthermore, some abiotic characteristics of soil changed $(\mathrm{pH}$ : from slightly acidic to neutral; reduction of electrical conductivity).

PMFCs were used to degrade petroleum and PAHs (phenanthrene and pyrene), using Aglaonema commutatum cv. Silver queen and surfactants ( $\beta$-cyclodextrin, Tween 80 and glucose) [27]. The latter are in fact able to enhance the hydrophobic pollutant solubility in soil [49], [50]. The results showed that the co-presence of the plant and surfactants significantly enhanced the PMFC efficiency in the petroleum removal from soil. Moreover, the degradation rate of the two PAHs significantly increased with increasing surfactant concentrations and in presence of the plants. The $\beta$-cyclodextrin addition more strongly enhanced PAH remediation. The charge-transfer resistance values in the PMFCs were significantly reduced with the two surfactants $\beta$-cyclodextrin and glucose. 
Until now, few works have been reported the role of PMFCs in bioremediation in field studies. There are some aspects to be evaluated and studied: plant viability, long term operation and rhizosphere mechanisms. Anyway, PMFCs have demonstrated their ability to remove contaminants and this technology is promising thanks to both the bioelectrochemical processes and the plant uptake.

\section{TECHNOLOGY OF MFC: ELECTRODES AND STRUCTURES}

In recent years, MFCs have been designed simplifying their structure and using more efficient and less expensive materials, making MFCs more sustainable electrical generation systems. For example, a reduction from two chambers to a single chamber, with the elimination of additional components such as the proton exchange membrane (PEM) was performed.

Anaerobic oxidation and extracellular electron transfer by specific microbes (e.g. Geobacteria), occur at the anode electrode, which works in anaerobic conditions. The cathode electrode is exposed to air, possibly also through an air-diffusion layer, and allows the transfer of oxygen for reduction reactions. Moreover, the oxygen reduction at the cathode electrode is advantageously supported with the aid of a catalytic binder layer [51].

The choice of materials and structure of the electrodes is very important to improve the electrical performance, in particular for electrical energy production. This is more evident for MFC, where output voltage values and intensity of current generated are low, normally insufficient to use MFC as power source directly connected to an electronic system to be powered.

Together with basic characteristics, such as a high conductivity obtained using pyrolyzed polymers, the best electrodes are nanostructured for increasing contact surface. In a fuel cell, a large surface area results, for example, in high reactivity with low material usage, useful for better catalysts [52]. A large surface area corresponds to a higher area of microbial activity, but the first priority is the use of materials showing biocompatibility for working bacteria. The opportunity for microorganisms to work in colonies and to produce conditions in which separate actions cooperate to produce enormous constructive results in terms of electricity generation. Further, a careful study on the geometry, composition, properties, and structure of the electrodes must be dedicated. Moreover, the biofilm development at the anode is crucial for the microbial cells activation. MFC without biofilm catalyst generates power density that is lower $2 \%$ than a mature biofilm [53]. The effect of biofilm growth is to decrease the anode impedance and facilitate electrochemical reactions: it also improves, in absence of mediators, the transfer of extracellular electrons from bacteria to anode electrode [54], increasing the generation of electricity. The growth of the biofilm itself is an indicator of better performance in terms of energy and potential clean-up capacity of the environment.

\subsection{Research to increase electrical performance}

The electrical performance depends on several factors that need to be controlled and optimized: extracellular electron transfer, biofilm growth and microbial adhesion to the surface of the anode substrate, reaction rate of oxygen reduction with oxygenation of the cathode substrate and ion transport. Many of these characteristics are related to the electrode properties. In recent years, the physical and chemical properties of the materials have been studied to be conveniently used as electrodes for MFCs. In particular, the choice was as objectives: biocompatibility of materials for promoting bacterial development, comprising a porous structure to increase the microbial adhesion area; chemical stability to avoid variations in functional conditions and keep the intensity of electricity generation constant; conductivity which must be as low as possible. For example, gold was adopted for its high conductivity 
and biocompatibility, eventually replaced by other metals with similar properties but with lower costs and simplified manufacturing. In particular, transition metals such as aluminium, copper, nickel, stainless steel and titanium have been used. The disadvantage of using metals for MFC electrodes is their passivation which hinders biofilm formation and microbial growth. Consequently, to obtain a better surface from the point of view of biocompatibility and electron transfer, materials based on carbon material were used. Since 2010, countless variants of electrodes based on this material have been proposed: carbon paper, graphite foil, carbon fibre well, polycrystalline carbon rod, carbon nanotube-textile, 3D carbon material, layered corrugated carbon, interlacing carbon yarn, activated carbon granules, granular activated carbon (GAC) particles, porous carbon with defined pore size, and so on [55]. In particular, the characteristic porosity of carbon-based materials naturally produces more power per geometric surface than the same material with a smooth surface. In addition to the properties of carbon-based materials that increase microbial adhesion to the anode substrate, conductivity, large effective surface area along with pore structure, techniques have been developed to form heteroatom-doped carbon that appear to improve performance of oxygen reduction. But the cost of such processes are high and a valid alternative low-cost has been recently studied that uses biomass-derived carbon [56]. Different solutions have been proposed to improve specific performance. For example, as regards the anode electrode, starting from a fabrication of the carbon cloth electrode, the adhesion of bamboo-like on nitrogen-doped carbon nanotubes has been proposed to improve biocompatibility and promote microbial adhesion to electrode [57]. Modifying electrodes with metal (or metal oxide) nanocomposite, such as titanium (Ti), manganese (Mn), and iron (Fe), allows the extracellular electron transfer from higher distances than a standard MFC electrode. Another example, the polyaniline (PANI) nanocomposite shows good and stable conductivity and the anode electrode produced with this nanocomposite exhibits better microbial adhesion [58]. Use of Poly(3,4-ethylenedioxythiophene) (PEDOT) is preferable when $\mathrm{pH}$ working conditions are wide and continuous redox activity is expected at the anode electrode [59].

\subsection{Research to improve remediation}

The proposal of an electrode modification has been cited previously, which realizes the adhesion of bamboo-like on nitrogen-doped carbon nanotubes in order to improve biocompatibility and promote microbial adhesion to the electrode. However, the goal of this change is mainly the electrical performance of the MFC. Li et al. [60] had an analogous objective but, aiming at the construction of carbon fibre electrodes, demonstrated to obtain that "effective range of remediation and the bioelectricity recovery was extended from 6 to $20 \mathrm{~cm}$ with the same area of air-cathode", referring to the bioelectrochemical remediation of petroleum hydrocarbons.

$\mathrm{Yu}$ et al. [22] examined the influence of electrode distance on PAH remediation rate in soils and using open soil MFC; removal rates of anthracene, phenanthrene, and pyrene significantly increased (from $21 \%, 17 \%$ and $12 \%$, to $54 \%, 43$ and $27 \%$ respectively). This was obtained using activated carbon fibre felt for both electrodes, and decreasing distance between anode and cathode electrodes from 10 to $4 \mathrm{~cm}$. Other studies focused on electrode modifications for improving contaminant degradation in the area where MFCs work [61].

An example of the methodology used by the authors is extensively described in a previous article of Borello et al. [1]. It refers to the application of MFC for degrading DDE, the main toxic metabolite of the pesticide DDT. In order to evaluate the effectiveness of the method, soil was sampled (30 cm depth) of an ex-agricultural area located in central Italy, with the following characteristics: $\mathrm{pH} 7,1.35 \%$ organic carbon and the texture was $28 \%$ sand, $24 \%$ 
silt and $48 \%$ clay. A municipal solid waste compost was mixed (3\%) with the soil to stimulate microbial community activity. Finally, a stock solution of DDE in acetone was diluted in distilled water and used to obtain a final DDE concentration of $1 \mathrm{mg} / \mathrm{kg}$ for each MFC.

The MFC used was a single-chamber type with a simplified configuration that uses graphite-based electrodes (anode and cathode) and does not require the use of semipermeable membranes. In this terrestrial MFC, the soil act as an electrolyte for the drift of hydrogen ions towards the cathode. Moreover, it provides both the bacterial community together with the nutrients existing naturally in the matrix. The anode was placed over a $1 \mathrm{~cm}$ layer of soil. Subsequently each chamber was filled with soil (at least $5 \mathrm{~cm}$ ), the soil was completely saturated with water in order to obtain anaerobic conditions; moreover the air bubbles removed. The cathode was then placed on the top of the soil and was exposed to air. An external circuit connected anode to cathode to make the electron movement. Using this scheme, the analysis of the percentage of DDE removal was carried out experimentally after 2, 6 and 12 months, obtaining values up to $46.6 \%$. The data were also compared to batches (in absence of cathode or anode electrodes, in order to find if the TMFC was more effectively in contaminant degradation.

\section{TMFCS USED IN LARGE SCALE AND OPEN FIELD APPLICATIONS}

As a matter of fact, a single TMFC/PMFC can provide low voltage and low power to supply ultra-low power electronic devices and transmitters [62]. Anyway, stacking MFCs allows to improve the output performance for large-scale applications. Unfortunately, there are possible issues to manage while stacking MFCs, as an example voltage reversal can occur. Pamintuan et al. [63] studied terrestrial PMFC with a combination of series and parallel connections in a stack. The combination of parallel and series configurations was the most efficient technique. Moreover, the voltage and current of stacking a few cells in series or parallel had a reduction in performances while increasing the number of cells connected linearly. Stacking of many cells in pure series or pure parallel connections is discouraged as voltage reversal can hinder the stack from reaching its theoretical potential.

Other reasons can bring to voltage reversal as several factors diversify the output of individual MFCs. The internal resistance and the construction design of reactors can be a key factor. Another way to reduce the losses due to differences between reactors connected in stack is to isolate each cell putting at the output of each cell a step-up converter instead of connecting all the cells together before the power management unit, which includes a single converter. The converter is always necessary to adapt the level of production of an MFC to the electrical needs of electronics devices. The power management comprises multiple DCDC converters for each MFC [64]. The energy harvesting in MFCs is performed by proper arrangement of DC-DC converters where every MFC is connected to DC-DC converters and the acquired energy is collected as high voltage in a single capacitor that supplies the load. In this system, MFCs are connected in series with a resistor to make the mean internal resistance.

In the last few years, some interesting new construction typology of MFC has risen up. Sudirjo et al. [65] tested PMFCs in both lab and in field studies. The practical configuration used was a tubular MFC used for large-scale applications without topsoil excavation. In this study, tubular plant-MFC (1 m length; width: anode: $19 \mathrm{~cm}$; cathode: $10 \mathrm{~cm})$ was installed in triplicate in a paddy field located in West Kalimantan, Indonesia. The plant-MFC reactors were installed in lines with a $30 \mathrm{~cm}$ distance between reactors. Interestingly, the spacer was made from non-conductive materials to prevent short circuiting, but was otherwise completely permeable. The tubular plant-MFCs generated electricity continuously during the crop season as long as the rice paddy is flooded. In one crop season, $9.5-15 \mathrm{Wh} / \mathrm{m}^{2}$ electricity 
was continuously generated with an average of $0.4 \pm 0.1 \mathrm{~mW}$ per meter tube. Between two crop seasons, plant-MFCs may be utilized in the form of biosensors as rain event indicators. A transparent silicon tube (VMQ silicone, 12/16 mm inner/outer diameter) was used to supply oxygen. Although this MFC configuration is very innovative, it needs improvements to be valuable as a depollution system for field studies, although it is a promising technology. The system also included a wireless sensor network based on the LoRa system that allowed long range of data transmitting, in this case the wireless transmission system was empowered with external batteries and solar panels.

\section{CONCLUSION}

Microbial fuel cells (MFCs) are considered as a promising system, which can generate electricity, mitigate greenhouse gas emissions and potentially recover soil from pollution. They have a low cost and are able to work for long periods. Terrestrial microbial fuel cells (TMFCs) are an alternative method for energy production using a large variety of substrates and materials for bioenergy production. TMFCs have been tested for removing pollutants (persistent organic contaminants and metals) from contaminated matrices thanks to the presence of microorganisms naturally present in soils that can use electrodes as electron acceptors during their metabolic activities.

TMFCs in field studies have a great potential for both soil recovery and develop of monitoring systems. The energy harvested can be useful to empower low power wireless sensor network nodes, permitting to collect and send data for environmental monitoring. TMFC efficiency have been usually limited in conventional MFC design, which submerges the anode in the soil and places the cathode above the soil surface. Especially in field studies, the conventional configuration allows the depollution of a little portion of the surface soil. Some limitations related to several construction characteristics of TMFCs such as the distance between the electrodes, the shape and the dimensions of the reactors have to be better investigate in order to improve the soil recovery.

\section{ACKNOWLEDGEMENTS}

We acknowledge the COST Action Horizon program and the COST Action PHOENIX CA19123: Protection, resilience, rehabilitation of damaged environment.

\section{REFERENCES}

[1] Borello, D. et al., Use of microbial fuel cells for soil remediation: A preliminary study on DDE. Int. J. Hydrog. Energy, 46, pp. 10131-10142, 2021.

[2] Di Lenola, M. et al., Combined effects of compost and Medicago sativa in recovery a PCB contaminated soil. Water, 12(3), p. 860, 2020.

[3] Ancona, V. et al., Microbial fuel cell: An energy harvesting technique for environmental remediation. Int. J. Environ. Impacts, 3(2), pp. 168-179, 2020.

[4] Tsipa, A., Varnava, C.K., Grenni, P., Ferrara, V. \& Pietrelli, A., Bio-electrochemical system depollution capabilities and monitoring applications: Models, applicability, advanced bio-based concept for predicting pollutant degradation and microbial growth kinetics via gene regulation modelling. Processes, 9(6), p. 1038, 2021.

[5] Wenzel, W.W., Rhizosphere processes and management in plant-assisted bioremediation (phytoremediation) of soils. Plant Soil, 321(1), pp. 385-408, 2009.

[6] Ramanjaneyulu, A.V., Neelima, T.L., Madhavi, A. \& Ramprakash, T., Phytoremediation: An overview. Applied Botany, eds R.M. Humberto, G.R. Ashok, K. Thakur \& N.C. Sarkar, American Academy Press, pp. 42-84, 2017. 
[7] Ancona, V., et al. Plant-assisted bioremediation: An ecological approach for recovering multi-contaminated areas. Soil Biological Communities and Ecosystem Resilience, eds M. Lukac, P. Grenni \& M. Gamboni, Springer, pp. 291-303, 2017.

[8] Ancona, V. et al., Plant assisted bioremediation: Soil recovery and energy from biomass. Assisted Phytoremediation, V. Pandey, Elsevier, 2021.

[9] Ancona, V. et al., Plant-assisted bioremediation of a historically PCB and heavy metal contaminated area in Southern Italy. New Biotechnol. 38, pp. 65-73, 2017.

[10] Ancona, V. et al., Heavy metal phytoremediation of a poplar clone in a contaminated soil in southern Italy. J. Chem. Technol. Biotechnol., 95, pp. 940-949, 2020.

[11] Ancona, V. et al., Poplar-assisted bioremediation for recovering a PCB and heavymetal-contaminated area. Agriculture, 11, p. 689, 2021.

[12] Barra Caracciolo, A. et al., Characterization of the belowground microbial community in a poplar-phytoremediation strategy of a multi-contaminated soil. Front Microbiol., 11, p. 2073, 2020.

[13] Ancona, V. et al., Gasification treatment of poplar biomass produced in a contaminated area restored using plant assisted bioremediation. J. Env. Manag., 239, pp. 137-141, 2019.

[14] Du, Z., Li, H. \& Gu, T., A state of the art review on microbial fuel cells: A promising technology for wastewater treatment and bioenergy. Biotechnol. Adv., 25, pp. 464482, 2007.

[15] Logan, B.E., Microbial Fuel Cells, John Wiley, 2008.

[16] Casula, E., Kim, B., Chesson, H., Di Lorenzo, M. \& Mascia, M., Modelling the influence of soil properties on performance and bioremediation ability of a pile of soil microbial fuel cells. Electrochimica Acta, 368, 137568, 2021.

[17] Abbas, S.Z. \& Rafatullah, M., Recent advances in soil microbial fuel cells for soil contaminants remediation. Chemosphere 272, 129691, 2021.

[18] Xu, X., Zhao, Q., Wu, M., Ding, J. \& Zhang, W., Biodegradation of organic matter and anodic microbial communities analysis in sediment microbial fuel cells with/without Fe (III) oxide addition. Biores. Technol. 225, pp. 402-408, 2017.

[19] Gustave, W. et al., Soil organic matter amount determines the behavior of iron and arsenic in paddy soil with microbial fuel cells. Chemosphere, 237, 124459, 2019.

[20] Pham, H., Boon, N., Marzorati, M. \& Verstraete, W., Enhanced removal of 1,2dichloroethane by anodophilic microbial consortia. Water Res., 43(11), pp. 29362946, 2009.

[21] Huang, D.Y., Zhou, S.G., Chen, Q., Zhao, B., Yuan, Y. \& Zhuang, L., Enhanced anaerobic degradation of organic pollutants in a soil microbial fuel cell. Chem. Eng. J., 172, pp. 647-653, 2011.

[22] Yu, B., Tian, J. \& Feng, L., Remediation of PAH polluted soils using a soil microbial fuel cell: influence of electrode interval and role of microbial community. J. Haz. Mat., 336, pp. 110-118, 2017.

[23] Miran, W., Nawaz, M., Jang, J. \& Lee, D.S., Chlorinated phenol treatment and in situ hydrogen peroxide production in a sulfate-reducing bacteria enriched bioelectrochemical system. Water Res., 117, pp. 198-206, 2017.

[24] Xu, X., Zhao, Q.L. \& Wu, M.S., Improved biodegradation of total organic carbon and polychlorinated biphenyls for electricity generation by sediment microbial fuel cell and surfactant addition. RSC Adv., 5, 62534, 2015.

[25] Cao, X., Song, H., Yu, C. \& Li, X., Simultaneous degradation of toxic refractory organic pesticide and bioelectricity generation using a soil microbial fuel cell. Biores. Technol. 189, pp. 87-93, 2015. 
[26] Sherafatmand, M. \& Ng, H.Y., Using sediment microbial fuel cells (SMFCs) for bioremediation of polycyclic aromatic hydrocarbons (PAHs). Biores. Technol., 195, pp. 122-130, 2015.

[27] Zhao, L., Deng, J., Hou, H., Li, J. \& Yang, Y., Investigation of PAH and oil degradation along with electricity generation in soil using an enhanced plant-microbial fuel cell. J. Cleaner Prod., 221, pp. 678-683, 2019.

[28] Li, X. et al., Long-term effect of biochar amendment on the biodegradation of petroleum hydrocarbons in soil microbial fuel cells. Sci. Total Env., 651, pp. 796-806, 2019.

[29] Lu, L., Huggins, T., Jin, S., Zuo, Y. \& Ren, Z.J., Microbial metabolism and community structure in response to bioelectrochemically enhanced remediation of petroleum hydrocarbon-contaminated soil. Environ. Sci. Technol., 48, pp. 4021-4029, 2014.

[30] Erable, B. et al., Application of electro-active biofilms. Biofouling, 26, pp. 57-71, 2010.

[31] Wu, M., Xu, X., Zhao, Q. \& Wang, Z., Simultaneous removal of heavy metals and biodegradation of organic matter with sediment microbial fuel cells. RSC Adv., 7, pp. 53433-53438, 2017.

[32] Mathuriya, A.S. \& Yakhmi, J.V., Microbial fuel cells to recover heavy metals. Environ. Chem. Lett., 12, pp. 483-494, 2014.

[33] Habibul, N., Hu, Y. \& Sheng, G.P., Microbial fuel cell driving electrokinetic remediation of toxic metal contaminated soils. J. Hazard. Mater., 318, pp. 9-14, 2016.

[34] Wang, H. et al., Bioelectrochemical remediation of $\mathrm{Cr}(\mathrm{VI}) / \mathrm{Cd}(\mathrm{II})$-contaminated soil in bipolar membrane microbial fuel cells. Env. Res., 186, 109582, 2020.

[35] Guana, C.-Y. et al., Wetland plant microbial fuel cells for remediation of hexavalent chromium contaminated soils and electricity production. J. Haz. Mat., 365, pp. 137$145,2019$.

[36] Wang, H. et al., New process for copper migration by bioelectricity generation in soil microbial fuel cells. Environ. Sci. Pollut. Control Ser., 23(13), pp. 13147-13154, 2016.

[37] Zhang, J. et al., Simultaneous enhancement of heavy metal removal and electricity generation in soil microbial fuel cell. Ecotox. Environ. Saf., 192, 110314, 2020.

[38] Habibul, N. et al., Bioelectrochemical chromium(VI) removal in plant-microbial fuel cells. Environ. Sci. Technol., 50, pp. 3882-3889, 2016.

[39] Zhang, J. et al., Effects of cathode/anode electron accumulation on soil microbial fuel cell power generation and heavy metal removal. Environ. Res., 198, 111217, 2021.

[40] Srivastava, P., Yadav, A.K. \& Mishra, B.K., The effects of microbial fuel cell integration into constructed wetland on the performance of constructed wetland. Bioresource Technol., 195, pp. 223-230, 2015.

[41] Lu, L. et al., Microbial community structure accompanied with electricity production in a constructed wetland plant microbial fuel cell. Biores. Technol., 195, pp. 115-121, 2015.

[42] Nitisoravut, R. \& Regmi, R., Plant microbial fuel cells: A promising biosystems engineering. Ren. Sust. Energy Rev., 76, pp. 81-89, 2017.

[43] Jadhav, D.A., Ghosal, D., Chendake, A.D., Pandit, S. \& Sajana, T.K., Plant microbial fuel cell as a biomass conversion technology for sustainable development. Catalysis for Clean Energy and Environmental Sustainability, eds K.K. Pant, S.K. Gupta \& E. Ahmad, Springer: Cham, 2021.

[44] Strik, D.P.B.T.B., Hamelers, H.V.M., Snel, J.F.H. \& Buisman, C.J.N., Green electricity production with living plants and bacteria in a fuel cell. Int. J. Energy Res., 32, pp. 870-876, 2008. 
[45] Helder, M. et al., Concurrent bioelectricity and biomass production in three plantmicrobial fuel cells using Spartina anglica, Arundinella anomala and Arundo donax. Biores. Technol., 101, pp. 3541-3547, 2010.

[46] Xiao, L. \& He, Z., Applications and perspectives of phototrophic microorganisms for electricity generation from organic compounds in microbial fuel cells. Ren. Sust. Energy Rev., 37, pp. 550-559, 2014.

[47] Yan, Z., Jiang, H., Cai, H., Zhou, Y. \& Krumholz, L.R., Complex interactions between the macrophyte Acorus calamus and microbial fuel cells during pyrene and benzo[a] pyrene degradation in sediments. Sci. Rep., 5, 10709, 2015.

[48] Deng, H., Chen, Z. \& Zhao, F., Energy from plants and microorganisms: Progress in plant-microbial fuel cells. Chem. Sus. Chem., 5, pp. 1006-1011, 2012.

[49] Li, X. et al., Sand amendment enhances bioelectrochemical remediation of petroleum hydrocarbon contaminated soil. Chemosphere, 141, pp. 62-70, 2015.

[50] Bardi, L, Mattei, A. \& Steffan, S., Hydrocarbon degradation by a soil microbial population with b-cyclodextrin as surfactant to enhance bioavailability. Enzyme Microb. Technol., 27, pp. 709-713, 2000.

[51] Wang, Z., Cao, C., Zheng, Y., Chen, S. \& Zhao, F., Abiotic oxygen reduction reaction catalysts used in microbial fuel cells. Chem. Electro. Chem., 1, pp. 1813-1821, 2014.

[52] Stamatin, I., Morozan, A. \& Dumitru, A., Nanostructured materials used for design the components of fuel cells. Rom. J. Phys., 49, pp. 767-775, 2004.

[53] Hou, B., Hu, Y.Y., Sun, J. \& Cao, Y.Q., Effect of anodic biofilm growth on the performance of the microbial fuel cell (MFC). 2010 4th International Conference Bioinforma. Biomed. Eng., pp. 1-4, 2010.

[54] Choudhury, P. et al., Performance improvement of microbial fuel cell (MFC) using suitable electrode and Bioengineered organisms: A review. Bioengineered., 8, pp. 471-487, 2017.

[55] Jayesh, M. et al., Recent advances in the development and utilization of modern anode materials for high performance microbial fuel cells. Biosens. Bioelectr., 90, pp. 558576, 2017.

[56] Yang, W. \& Chen, S., Biomass-derived carbon for electrode fabrication in microbial fuel cells: A review. Ind. Eng. Chem. Res., 59, pp. 6391-404, 2020.

[57] Ci, S., Wen, Z., Chen, J. \& He, Z., Decorating anode with bamboo-like nitrogen-doped carbon nanotubes for microbial fuel cells. Electrochem. Commun., 14, pp. 71-74, 2012.

[58] Wang, P., Li, H. \& Du, Z., Polyaniline synthesis by cyclic voltammetry for anodic modification in microbial fuel cells. Int. J. Electrochem. Sci., 9, pp. 2038-2046, 2014.

[59] Kang, Y.L., Ibrahim, S. \& Pichiah, S., Sinergetic effect of conductive polymer poli(3,4-ethylenedioxythiophene) with different structural configuration of anode for microbial fuel cell application. Bioresour. Technol., 189, pp. 364-369, 2015.

[60] Li, X. et al., Carbon fiber enhanced bioelectricity generation in soil microbial fuel cells. Biosens. Bioelectron., 85, pp. 135-141, 2016.

[61] Logan, B.E., Rabaey, K., Conversion of wastes into bioelectricity and chemicals by using microbial electrochemical technologies. Science, 337, pp. 686-690, 2012.

[62] Rajeev, P. et al., Plug into a plant: Using a plant microbial fuel cell and a wake-up radio for an energy neutral sensing system. Proceedings of 2017 IEEE 42nd Conference on Local Computer Networks Workshops (LCN workshops), IEEE Press, Singapore, pp. 18-25, 2017. 
[63] Pamintuan, K. et al., An analysis of the stacking potential and efficiency of plantmicrobial fuel cells growing green beans (Vigna ungiculata ssp. sesquipedalis). Int. J. Renew. Energy Develop., 9, pp. 439-447, 2020.

[64] Saravanakumar, K. \& Rajeswari, R., Microbial fuel cell-based self-powered biosensor for environment monitoring in IoT cloud framework. Concurrency Comput. Pract. Ex., 31(15), e5165, 2019.

[65] Sudirjo, E. et al., Performance and long distance data acquisition via LoRa technology of a tubular plant microbial fuel cell located in a paddy field in West Kalimantan, Indonesia. Sensors 19(21), p. 4647, 2019. 